\title{
FEATURES OF THE COURSE OF PERINATAL INFECTIONS AT THE PRESENT STAGE
}

10.36740/WLek202010132

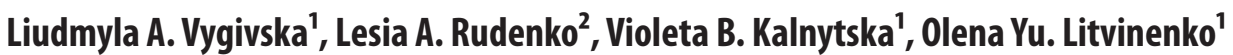 \\ 'KHARKIV NATIONAL MEDICAL UNIVERSITY, KHARKIV, UKRAINE \\ 22ALUNA PUBLISHING HOUSE, KONSTANCIN-JEZIORNA, POLAND
}

\begin{abstract}
The aim: To characterize the course of the most common perinatal infections on the basis of assessment of the literature data.

Materials and methods: This article provides an assessment of 125 literature sources submitted to PubMed, Medline, Cochrane Library, CyberLeninka, Google Scholar and V.I. Vernadsky National Library of Ukraine. The description of the most common viral, bacterial and parasitic perinatal infections, transmission methods, clinical manifestations, methods of diagnosis and treatment, their clinical consequences are described. Perinatal infections are the leading cause of severe congenital pathology, a serious worldwide medical and social problem that needs to be addressed.

Conclusions: Perinatal infections are a serious issue of today, requiring a multidisciplinary approach and the collaboration of doctors of different specialties. Their prevalence among the population, high rates of perinatal mortality, concealment under the mask of other disorders, and the absence of specific clinical symptoms in pregnant and newborns require careful consideration of this problem. Improving the quality of diagnosis and treatment of this pathological condition will help to minimize the risk of transmission of infection, as well as to avoid a number of abnormaalities in the neonatal period and the development of congenital infection.
\end{abstract}

KEY WORDS: perinatal infections, routes of transmission, diagnosis, treatment, prevention

Wiad Lek. 2020;73(10):2269-2276

\section{INTRODUCTION}

Perinatal infections often play a leading role in the causes of such adverse effects of pregnancy as stillbirth, early infant death and morbidity, which makes it important to study this issue comprehensively. Infections cause the termination of every fifth pregnancy. The term "perinatal infection" usually refers to infections transmitted from the mother to the infant during prenatal development (prenatal or congenital infections), during childbirth (perinatal or intranatal infections), as well as immediately after birth (postnatal infections).

Currently, perinatal infections include sexually transmitted infections, vaginal dysbiosis and TORCH syndrome infections. In addition, there are new infections that were not previously known to mankind, a disease caused by parvovirus B19, herpes virus type 6 , etc. [1-2].

The number of children born with signs of intrauterine infection from pregnant women with infectious-inflammatory diseases does not tend to decrease, but on the contrary, increases, ranging from 10 to $58 \%$ [3].

Management of perinatal infections is a difficult task because of the absence of apparent specific symptoms inherent to a particular pathology, as well as the correlation between the severity of infectious pathology of the pregnant woman and the involvement of the fetus [4]. Newborns with clinical manifestations of infection require costly therapy and further rehabilitation, which does not completely exclude the development of the pathological process into chronic form and even complete disability of the child. Both mother and fetus often have mixed forms of viral-bacterial infections, which dictates the need for therapeutic measures aimed at increasing nonspecific resistance of the body and correction of metabolic changes [5].

Today, thanks to vaccination, it is possible to control such infections as viral hepatitis $B$, rubella, measles, mumps. Bacterial and sexually transmitted infections are also controlled through the use of effective antibacterial agents. A large number of perinatal infections can now also be controlled using certain chemotherapeutic agents. Some women have such infections as cytomegaly or toxoplasmosis in childhood, and by the reproductive period they acquire natural immunity [6].

However, it should be noted that, despite vaccination, such infections as genital herpes, papillomavirus infection, and parvovirus B19 infection are not sufficiently controlled.

The solution to the problem of perinatal infections is their prevention during pregravid preparation by vaccination, elimination of pathogens and stabilization of chronic diseases such as herpes simplex virus. This approach requires the collaboration of specialist physicians (obstetrician, gynecologist, infectious disease specialist) to adequately assess the risks to the mother and child and to prescribe therapy.

\section{THE AIM}

To characterize the course of the most common perinatal infections on the basis of assessment of the literature data. 


\section{MATERIALS AND METHODS}

This article provides assessment of 125 literary sources. Particular attention is paid to sources over the last 5 years (2014-2019), but some earlier publications that have not lost their relevance are also included in the review. The sources were taken from scientific metric databases PubMed, Medline, databases of electronic libraries Cochrane Library, CyberLeninka, search engine Google Scholar and the portal of scientific periodicals of V.I. Vernadsky National Library of Ukraine. The description of the most common viral, bacterial and parasitic perinatal infections, transmission methods, clinical manifestations, methods of diagnosis and treatment, their clinical consequences are presented. Perinatal infections are a leading cause of severe congenital pathology, a serious worldwide medical and social problem that needs to be addressed [7-8].

\section{REVIEW AND DISCUSSION}

Perinatal infections are a topical issue today because: in the structure of perinatal mortality, the proportion of intrauterine infection ranges from 2 to $65.6 \%$; the structure of infectious morbidity of pregnant women, the fetus and the newborn has changed; the role of pathogens of sexually transmitted diseases has increased dramatically; the problem of diagnosis of this disorder (often hidden by such diagnoses as intrauterine hypoxia, asphyxia, birth trauma) remains extremely important and complicated [9].

Up to 2500 different infections are known in modern medical science. Proven pathogens for intrauterine infections are over 27 species of bacteria, viruses, parasites, 6 species of fungi, 4 types of protozoa and rickettsia. There is no relationship between the severity of the infectious process in the mother and the fetus.

Current perinatal care guidelines developed by the American Academy of Pediatricians and the American College of Obstetricians and Gynecologists suggest that only some infections occurring during the pre- and intranatal period can significantly affect the fetus and the newborn [10].

\section{VIRAL INFECTIONS}

Cytomegalovirus infection (CMV) is one of the most common perinatal infections. $1 \%$ of newborns are infected with CMV pre-natally, and the virus is released after birth. Signs of infection are observed from birth in $10 \%$ of newborns with congenital CMV infection [11-12]. Thus, intrauterine growth retardation, jaundice, purpura, hepatosplenomegaly, microcephaly, intracerebral calcifications, retinitis, and neurosensory hearing loss are detected in one third of all cases [13]. CMV is the main non-genetic cause of neurosensory hearing loss [14]. Ways of transmission: transplacental, contact with infected mother's secretions, swallowing of infected breast milk, blood transfusions from seropositive donors. Infection occurs from mothers with primary CMV infection, primarily from those infected in the first and second trimesters [15].
The benefit of routine serological screening of women or newborns has not yet been proven [16]. Testing is carried out only to pregnant women and newborns with suspected CMV.

Isolation of the virus or detection of the CMV genome by polymerase chain reaction (PCR) from amniotic fluid is the most sensitive test for the detection of fetal infection. In addition, cord blood obtained by cordocentesis can be tested for CMV-specific immunoglobulin M (IgM), but this test is less sensitive than the release of culture or PCR of amniotic fluid [17].

Today, the treatment of CMV infection in clinically healthy people is not carried out. Antiviral treatment is provided to patients whose condition is life-threatening. The use of hyperimmune globulin in pregnant women with primary $\mathrm{CMV}$ infection may reduce the risk of congenital CMV [18].

However, insufficient data have yet been collected on its effectiveness, which makes it difficult to recommend for widespread use.

Enteroviruses. They include a group of viruses: polioviruses, Coxsackie viruses, echoviruses and other enteroviruses.

The widespread use of the vaccine has helped to eliminate poliovirus infection.

Enterovirus infection is spread by fecal-oral route and through the air. Enteroviruses are common and pregnant women are often exposed to them, especially in the summer and autumn months. Most of the enterovirus infections during pregnancy are mild or asymptomatic. However, in the third trimester, infection can be the cause of the onset of labor [19]. Enteroviruses penetrate the placenta and cause disease in the fetus and antenatal death. Vertical transmission of enteroviruses can occur at birth under the influence of a virus contained in maternal blood or vaginal secretions. Signs of enterovirus infection in newborns are usually observed 3-7 days after birth. In newborns, manifestation may include pneumonia, rash, aseptic meningitis, encephalitis, paralysis, hepatitis, conjunctivitis, myocarditis, and pericarditis [20].

The diagnosis is confirmed by isolation of the virus from smears from the throat or rectum and samples of feces, cerebrospinal fluid or blood.

Herpes simplex virus. Herpes simplex virus (HSV) is a DNA virus. Types 1,2 and 6 are relevant in obstetrics [21]. Most sexually transmitted infections with HSV are caused by HSV-2. However, HSV-1 is increasingly the cause of genital herpes infection [22].

In $60 \%$ of cases the course is asymptomatic, in $20 \%$ atypical, and 20\% have typical clinical signs of the disease [23]. There are primary infection and relapses. Primary infection occurs in women without evidence of previous herpetic infection (i.e. seronegative for both HSV-1 and HSV-2) or primary infection of HSV-2 in women with prior HSV-1 infection or vice versa [24]. In relapses, infections occur in women with clinical or serological data from previous genital herpes (the same serotype) [25].

The fact that HSV-2 infection is confirmed serologically but not clinically diagnosed in most women is indicative of the asymptomatic course of most primary infections [26]. 
Women with primary HSV infection which develop at late stages of pregnancy (symptomatic or asymptomatic) who give birth vaginally are at high risk (30-50\%) of transmitting the virus to their children. The risk of transmission during vaginal birth is much lower in recurrent infection (less than 2-5\%).

Although routine HSV screening is not recommended, all suspected herpes virus infections should be evaluated and confirmed using methods of virus detection (viral culture or viral PCR detection of the antigen) or a test for a specific serological antibody [27].

In Ukraine, according to the order No. 906 "Perinatal infections" as of 27.12.2006, treatment with antiviral drugs is not carried out, except in cases when it is urgently indicated to the mother.

Foreign scientists have shown that the use of acyclovir in pregnant women reduces the risk of clinical recurrence of HSV. Acyclovir can be given orally to pregnant women with a first episode of genital herpes or severe recurrence of herpes infection. Intravenous administration is indicated in severe genital HSV infection or with disseminated herpetic infection [28]. Pre-natal infection is extremely rare. Most children who develop HSV infection acquire it during the passage through the infected maternal lower genital tract or premature rupture of the fetal membranes when the ascending infection occurs [29]. Signs of infection appear within 48 hours of birth [30].

Human papillomavirus. Human papillomavirus (HPV) infections are common. There are more than 100 types of HPVs, more than 40 of which can infect the genital area.

HPV-6 and HPV-11 are the cause of respiratory papillomatosis, HPV-16 and HPV-18 contribute to genital carcinoma [31]. Most cervical HPV infections are sexually transmitted and have an asymptomatic course. Genital HPV infections can be exacerbated during pregnancy. Imiquimod, sinecatechins, podophyllin, and podofilox drugs should not be used during pregnancy because they have a toxic effect on the fetus. Cryotherapy, laser therapy and trichloroacetic acid can be safely used in the treatment of HPV during pregnancy [32]. FDA-approved vaccines have no adverse effect on pregnancy. However, if a woman becomes aware that she is pregnant at the time of vaccination, it must be postponed until delivery. Vaccination is not contraindicated when breast-feeding [33].

There is a risk of transmission of HPV from mother to child. The risk of transmission of recurrent respiratory papillomatosis is very low.

Aspiration of infectious secretions can occur during the passage through the birth canal. In large condylomas caesarean section is recommended as they contribute to the deterioration of vaginal stretching during childbirth, and can also cause large vulvovaginal ruptures.

Human parvovirus. Parvovirus B19 is a DNA virus that causes exanthema in children.

Transmission is most often through air and by contact routes, that is, through the airways and from hand to mouth. In $33 \%$ of cases the infection is asymptomatic [34]. Most people carry the infection in a mild form and completely recover.

\section{Perinatal transmission.}

Parvovirus B19 affects fetal erythrocytes and causes anemia, which can lead to non-immune dropsy, isolated pleural and pericardial effusions, fetal developmental delay and death syndrome. Future parents should be aware that, although the rate of intrauterine transmission is high (approximately 50\%), the risk of fetal death is between 2\% and $6 \%[35]$.

Most reported perinatal infections caused by parvovirus lead to fetal death when infection occurs between the $10^{\text {th }}$ and $20^{\text {th }}$ weeks of pregnancy, fetal death or miscarriage usually occurs 4-6 weeks after infection [36]. Congenital abnormalities caused by parvovirus are extremely rare. The teratogenic effect of parvovirus has not been proven [37]. Due to the prevalence of asymptomatic parvovirus infection in adults and children, all pregnant women are at some risk of infection. If a pregnant woman becomes aware that she has been in contact with a patient, the potential risk to the fetus should be assessed and a serological test (ELISA and Western blot tests) should be carried out. If the test is negative, it should be repeated in 3-4 weeks to determine seropositivity [38].

When seroconversion occurs, the fetus should be monitored for 10 weeks by serial ultrasound to assess the presence of non-immune fetal hydrops, placenta and growth disorders [39]. In the development of fetal hydrops, it is recommended to perform umbilical cord blood sampling with determination of hematocrit, leukocytes and platelets, as well as viral DNA to choose strategy for pregnancy management and subsequent treatment of the newborn [40].

Rubella. Rubella during pregnancy can lead to miscarriage, fetal death, or congenital rubella syndrome. The most common manifestations associated with congenital rubella syndrome are ophthalmic (cataracts, pigmented retinopathy, microphthalmus and congenital glaucoma), cardiac (open arterial duct, pulmonary artery stenosis), auditory (neurosensory disorders of hearing) and neurological (behavioral disorders, meningoencephalitis and mental retardation). Mild forms of congenital rubella syndrome may be associated with minor clinical manifestations at birth [41].

At the preconception stage, it is desirable to undergo serological screening for immunity to rubella [42]. Seronegative women should be vaccinated. Vaccination against rubella is carried out by live attenuated cultures, is very effective and has few side effects. However, vaccination against rubella is not recommended during pregnancy. Breastfeeding is not a contraindication for vaccination. After vaccination within 1 month, conception is not recommended. However, if a woman becomes pregnant within 1 month of vaccination against rubella, or is accidentally vaccinated early in pregnancy, she should be informed of the potential teratogenic risk to the fetus [43].

If a pregnant woman is diagnosed with rubella, she should be advised of the risk of infecting the fetus and decide whether it is necessary to terminate the pregnancy. Structural anomalies can be caused by infection during embryogenesis [44]. If the infection occurs after the $20^{\text {th }}$ week of pregnancy, birth defects rarely develop. All newborns 
with signs of congenital rubella or those born to women who had rubella during pregnancy should be isolated for further examination and treatment [45].

Varicella zoster virus. Varicella zoster virus (VZV) is a highly contagious DNA herpesvirus that is transmitted through the air and by contact route.

Varicella in pregnant women can lead to the transmission of a fetal virus or newborn. It can cause congenital varicella syndrome, which is manifested by low birth weight, skin scars, limb hypoplasia, microcephaly, chorioretinitis and cataracts, neurological disorders [46]. It is observed in 1.5\% of children born to women who had the disease before 28 weeks of gestation. If the infection occurred on the eve of childbirth (5 to 2 days), newborns develop a severe form of varicella, which has a high mortality rate [47-48]. VZV in the mother is usually diagnosed on the basis of clinical data and laboratory testing is not required. Pregnant women with severe varicella should be hospitalized with administration of acyclovir [49-50].

\section{BACTERIAL INFECTIONS}

Chlamydial infection. Chlamydia trachomatis is the most common sexually transmitted infection. It is especially widespread among sexually active adolescents and young people (15-24 years old) [51]. Infected women have few symptoms, but $C$. trachomatis can cause urethritis and mucous-purulent (non-cancerous) cervicitis. Chlamydial infection is also associated with postpartum endometritis and infertility. The infection can be transmitted to the newborn during the passage through the birth canal. Clinical manifestations in fetuses/newborns: low birth weight, conjunctivitis, pneumonia [52-53]. Pre-conceptual counseling should include testing for chlamydial infection. High-risk women should be re-examined in the third trimester. The diagnosis of $C$. trachomatis infection is based on enzyme-linked immunosorbent assay and PCR.

Treatment is carried out both to the woman and to the sexual partner according to specially developed schemes (josamycinum $500 \mathrm{mg}$ orally 3 times a day for 7 days or 1 $\mathrm{g}$ of azithromycin orally in a single dose or amoxicillin 500 mg orally three times a day for 7 days) [54].

Gonorrhea. It is also one of the most common sexually transmitted infections. Women as young as 25 are at highest risk of contracting gonorrhea. New or multiple sexual partners, misuse of condoms, commercial sex work, and illicit drug use are among causes of infection [55].

Gonococcal genital tract infections in women are often asymptomatic. Common clinical syndromes are vaginitis, urethritis, endocervicitis and salpingitis. Asymptomatic infection in women can develop into a more severe disease involving pelvic organs, such as inflammation of the pelvis with obstruction of the fallopian tubes, resulting in ectopic pregnancy or infertility [56]. Women at risk should be screened for gonorrhea.

It is characterized by premature discharge of amniotic fluid, premature delivery. It may cause preterm death of fetus, gonoblenorrhea and sepsis in newborns [57]. Endo- cervical or vaginal smears as well as urinalysis are used for diagnosis. PCR diagnosis is a highly sensitive and specific method for detecting gonorrhea [58-59].

Group B streptococci. Group B (GBS) streptococci, also known as Streptococcus agalactiae, have been a major cause of perinatal morbidity and mortality since the 1970s, despite the fact that streptococci are a pathogen [60]. Vaginal or rectal colonization with Streptococcus agalactiae is observed in $10-40 \%$ of pregnant women [61].

Group B streptococci can cause maternal urinary tract infection, amnionitis, endometritis, sepsis, and less commonly, meningitis. Vertical transmission of infection during childbirth can lead to infection of newborns within the first 6 days after birth, characterized primarily by sepsis or pneumonia, and less commonly by meningitis [62].

Introduction of national guidelines for administration of antibiotics during childbirth in the 1990s reduced early sepsis in newborns caused by Streptococcus agalactiae by $80 \%$. However, even today GBS remains the leading cause of infant mortality and morbidity [63]. The main risk factors for infections in newborn are: presence of infection in the mother, gestational age of less than 37 weeks, premature rupture of the fetal membranes for 18 hours or more, intra-amniotic infection, young maternal age and the presence of pessary [64].

In 2010, Centers for Disease Control and Prevention reviewed the basic principles for preventing early-onset infection caused by Streptococcus agalactiae: antenatal screening for infection at 35-37 weeks of gestation, timely antibiotic prophylaxis, especially in women with the risk of preterm labor [65].

Listeriosis. The major cause of epidemic and sporadic listeriosis infection is the food transmission of Listeria monocytogenes. Listeriosis is a food-borne infection. The bacterium enters the human body with food, which in turn is infected during manufacture and storage. These products include unpasteurized milk, cheese and other dairy products; undercooked poultry meat, cooked meat (hot dogs, meat delicacies and pate) [66].

Published on 21 February 2017, the results of a study by the Madison School of Veterinary Medicine (USA) showed that listeriosis can lead to miscarriage early in pregnancy (first trimester) [67]. Earlier listeriosis was recognized only in the third trimester and its effect at an early stage has not been studied. Sepsis is an early manifestation of infection in newborns and meningitis a late one [68]. Pregnant women are not recommended to consume unpasteurized dairy products, unwashed fresh fruits and vegetables, and under-processed meat to prevent listeria infection [69]. The role of Listeria as a causative agent of human diseases can be characterized as follows: they are causative agents of food infection; agents of a wide range of opportunistic infections; cause of human perinatal and neonatal pathology.

Serological test is suggested to detect the presence of anti-listeriolysin $\mathrm{O}$ antibodies in blood [70]. Treatment includes administration of macrolides [71]. 


\section{PARASITIC INFECTIONS}

Malaria. Although malaria is largely restricted to tropical regions in Africa, Asia, and Latin America, frequent international travel and migration have made it a disease that cannot be ignored in developed countries [72].

Malaria infection is quite a serious condition for pregnant women, due to the increased risk of adverse pregnancy outcomes, including spontaneous abortion, stillbirth, premature birth and low birth weight [73-75]. Due to the high risk for both the woman and the fetus, as well as the lack of full effect of chemoprevention on pregnant women and women planning pregnancy, travel to areas endemic to malaria should be avoided. Congenital malaria is rare. Signs and symptoms resemble newborn sepsis.

Toxoplasmosis. Toxoplasmosis is a protozoal infection caused by Toxoplasma gondii. It is an infectious disease. Ways of transmission can be nutritional, zoonotic and from mother to child during pregnancy.

Infected women are usually asymptomatic. Signs of a congenital infection can show up at birth. These include maculopapular rash, generalized lymphadenopathy, hepatosplenomegaly, chorioretinitis, hydrocephalus, microcephaly, and intracranial calcification [76].

Routine serological screening is not indicated for pregnant women, except in cases of HIV infection, since the presence of antibodies indicates immunity, especially if the woman is at risk before conception [77]. The diagnosis of maternal infection is based on the results of a serological test for the detection of toxoplasmospecific antibodies [78]. Patients with suspected toxoplasmosis should be tested for immunoglobulins IgG and IgM [79]. A positive $\operatorname{IgG}$ titer indicates past infection. A negative IgM test essentially eliminates recent infection, but a positive IgM test is difficult to interpret because toxoplasma-specific IgM antibodies can be detected within 18 months of acute infection. (More information on laboratory diagnosis of toxoplasmosis is available on the CDC website at http:// www.dpd.cdc.gov/dpdx/HTML/Toxoplasmosis.htm).

Treatment of pregnant with acute toxoplasmosis reduces but does not exclude the risk of congenital infection. Detection of acute maternal infection requires immediate start of treatment prior to evaluation of fetal status. Spiramycin accumulated in the placenta can reduce the risk of fetal transmission by $60 \%$. If intrauterine infection is confirmed, it is recommended to add pyrimethamine, sulfanilamides (which is an exception only to congenital toxoplasmosis) and folic acid to the treatment regimen, which may contribute to a successful pregnancy outcome [80].

\section{CONCLUSIONS}

Perinatal infections are a serious issue of today, requiring a multidisciplinary approach and the collaboration of doctors of different profiles. Prevalence among the population, high rates of perinatal mortality, concealment under the mask of other disorders, and the absence of specific clinical symptoms in pregnant and newborns require careful consideration of this problem. Improving the quality of diagnosis and treatment of this pathological condition will help to minimize the risk of transmission of infection, as well as to avoid a number of pathological conditions in the neonatal period and the development of congenital infection.

\section{REFERENCES}

1. Keighley C.L., Skrzypek H.J., Wilson A. et al. Infections in pregnancy. 2019;211(3):134-41. doi: 10.5694/mja2.50261.

2. Leeper C., Lutzkanin A. 3rd. Infections During Pregnancy. Prim Care. 2018;45(3):567-86. doi: 10.1016/j.pop.2018.05.013.

3. Zaplatnikov A.L., Korovin N.A., Korneva M.Yu., Cheburkin A.V. Vnutriutrobnye infekcii:diagnostika, lechenie, profilaktika [Intrauterine infection: diagnosis, treatment, prevention]. MNS;2013:1(48): 25-33. (Ru)

4. Sidorova .I.S, Makarov I.0., Matvienko N.A. Vnutriutrobnaya infekciya: vedenie beremennosti, rodov i poslerodovogo perioda [Intrauterine infection: management of pregnancy, childbirth and the puerperium]. Moskva: MEDpress-inform; 2012. (Ru)

5. Strebkova E.D., Gazazyan M.G. Kliniko-morfologicheskie paralleli pri vnutriutrobnom inficirovanii [Clinical and morphological parallels in cases of intrauterine infection]. Health and Education in the XXI Century. 2016;1:5-11. (Ru)

6. Thackeray R., Magnusson B.M. Women's attitudes toward practicing cytomegalovirus prevention behaviors. Prev Med Rep. 2016;4:517-24.

7. Kholodnova N.V., Mazankova L.N., Volter A.A., Turina I.E. Sovremennyj vzglyad na problemu vrozhdennoj citomegalovirusnoj infekcii: diagnostika, lechenie i profilaktika [The modern view of congenital cytomegalovirus infection: diagnosis, treatment and prevention]. Children infections. 2019;18(4):56-63. (Ru)

8. Shcherbina N.A., Vygivska L.A. The state of immunity in pregnancies complicated by intrauterine infection of the fetus. Dev Period Med. 2017;21(4):384-9.

9. Williams C.L., Harrison, Llata, Smith R.A., Meites E. Sexually Transmitted Diseases Among Pregnant Women: 5 States, United States, 2009-2011. Matern Child Health J. 2018;22(4):538-545. doi: 10.1007/s10995-0172422-9.

10. Racicot K., Mor G. Risks associated with viral infections during pregnancy. J Clin Invest. 2017;127(5):1591-9. doi: 10.1172/JC187490.

11. Dietrich M.L., Schieffelin J.S. Congenital Cytomegalovirus Infection. Ochsner J. 2019;19(2):123-30. doi: 10.31486/toj.18.0095.

12. Medley N., Vogel J.P., Care A., AlfirevicZ. Interventions during pregnancy to prevent preterm birth: an overview of Cochrane systematic reviews. Cochrane Database Syst Rev. 2018;11:CD012505. doi: 10.1002/14651858.CD012505.pub2.

13. ToriiY.,Yoshida S.,YanaseY. etal. Serological screening of immunoglobulin $M$ and immunoglobulin $\mathrm{G}$ during pregnancy for predicting congenital cytomegalovirus infection. BMC Pregnancy Childbirth. 2019;19(1):205. doi: 10.1186/s12884-019-2360-1.

14. Joob B., Wiwanitkit V. Sensorineural Hearing Loss and Congenital Cytomegalovirus Infection. J Pediatr Genet. 2018;7(1):45. doi: 10.1055/s-0037-1612599.

15. Pass R.F., Arav-Boger R. Maternal and fetal cytomegalovirus infection: diagnosis, management, and prevention. F1000Res. 2018;7:255. doi: 10.12688/f1000research.12517.1.

16. Hwang J.S., Friedlander S., Rehan V.K. et al. Diagnosis of congenital/ perinatal infections by neonatologists: a national survey. J Perinatol. 2019:39:690-6. doi: 10.1038/s41372-019-0364-3. 
17. Ohyama S., Fujioka K., Fukushima S. et al. Diagnostic Value of Cytomegalovirus IgM Antibodies at Birth in PCR-Confirmed Congenital Cytomegalovirus Infection. Int J Mol Sci. 2019;20(13). pii: E3239. doi: 10.3390/ijms20133239.

18. Nigro G., Adler S.P. Congenital Cytomegalic Disease Collaborating Group. High-dose CMV hyperimmune globulin (HIG) and maternal CMV DNAemia independently predict infant outcome in pregnant women with a primary cytomegalovirus (CMV) infection. Clin Infect Dis. 2019. pii: ciz1030. doi: 10.1093/cid/ciz1030.

19. Khediri Z., Vauloup-Fellous C., Benachi A. et al. Adverse effects of maternal enterovirus infection on the pregnancy outcome: a prospective and retrospective pilot study. Virol J. 2018;15(1):70. doi: 10.1186/ s12985-018-0978-7.

20. Korhonen L., Seiskari T., Lehtonen J. et al. Enterovirus infection during pregnancy is inversely associated with atopic disease in the offspring. Clin Exp Allergy. 2018;48(12):1698-704. doi: 10.1111/cea.13280. 37

21. Vygivska L.A., Tuchkina I.0., Kalnytska V.B. The impact of emergent infections on the fetal state. Wiad Lek. 2017;70(4):731-36.

22. Rechenchoski D.Z., Faccin-Galhardi L.C. et al. Herpesvirus: an underestimated virus. Folia Microbiol. (Praha). 2017;62(2):151-6.

23. Dyudyun A.D. Obshie principy diagnostiki i lecheniya bolnyh gerpesvirusnoj infekciej (klinicheskaya lekciya) [General principles of the diagnostics and treatment of patients with herpes virus infection (a clinical lecture)]. Dermatovenereology. Cosmetology. Sexopathology. 2016;1-4:118-55. (Ru)

24. Lee R., Nair M. Diagnosis and treatment of herpes simplex 1 virus infection in pregnancy. Obstet Med. 2017;10(2):58-60. doi: $10.1177 / 1753495 \times 16689434$.

25. Feltner C., Grodensky C., Ebel C. et al.Serologic Screening for Genital Herpes: An Updated Evidence Report and Systematic Review for the US Preventive Services Task Force. JAMA. 2016;316(23):2531-43. doi: 10.1001/jama.2016.17138.

26. Ovchinnikova M.A., Lipatov I.S., Santalova G.V., Tezikov Y.V. Vliyanie metoda profilaktiki vnutriutrobnogo inficirovaniya na sostoyanie nespecificheskogo immuniteta u beremennyh s recidiviruyushim techeniem gerpeticheskoj infekcii i ih detej. [The impact of the method of prevention of intrauterine infection on the state of nonspecific immunity in pregnant women with relapsing herpetic infection and their children]. Journal Infectology. 2018;10(1):70-79. (Ru)

27. Vauloup-Fellous C. Genital herpes and pregnancy: serological and molecular diagnostic tools. Guidelines for clinical practice from the French College of Gynecologists and Obstetricians (CNGOF). Gynecol Obstet Fertil Senol. 2017;45(12):655-63. doi: 10.1016/j. gofs.2017.10.004.

28. Patel R., Kennedy 0.J., Clarke E. et al. 2017 European guidelines for the management of genital herpes. Int J STD AIDS. 2017;28(14):1366-79. doi: 10.1177/0956462417727194.

29. Patel C.D., Backes I.M., Taylor S.A. et al. Maternal immunization confers protection against neonatal herpes simplex mortality and behavioral morbidity. Sci Transl Med. 2019;11(487). pii: eaau6039. doi: 10.1126/ scitransImed.aau6039.

30. Sénat M-V., Anselem 0., Picone 0. et al. Prevention and management of genital herpes simplex infection during pregnancy and delivery: Guidelines from the French College of Gynaecologists and Obstetricians (CNGOF). Eur J Obstet Gynecol Reprod Biol. 2018;224:93-101.

31. Pandey D., Solleti V., Jain G. et al. Human Papillomavirus (HPV) Infection in Early Pregnancy: Prevalence and Implications. Infect Dis Obstet Gynecol. 2019;2019:4376902. doi: 10.1155/2019/4376902.
32. Zhukembaeva A.M. Infekcii, peredayushiesya polovym putem pri beremennosti: vliyanie na ee ishod, vozmozhnosti profilaktiki i lecheniya [Infections, sexually transmitted during pregnancy: impact on its outcome, the possibility of prevention and treatment]. Vestnik KyrgyzskoRossijskogo Slavyanskogo universiteta. 2016;16(11):115-7. (Ru)

33. Human papillomavirus vaccination. Committee Opinion No. 467. American College of Obstetricians and Gynecologists. Obstet Gynecol 2010;116:800-03. doi: 10.1097/A0G.0b013e3181f680c8.

34. Dziublyk I.V., Kovaliuk 0.V. Parvovirus V19 ta yoho rol u patolohii liudyny [Parvovirus B19 and its role in human pathology]. Semeinaia medytsyna. 2015;3(59):193. (UA)

35. Tovo P.A., Bezzio S., Gabiano C. Fetal Infections: Rubella, HIV, HCV, HBV, and Human Parovirus B19. In: Buonocore G, Bracci R, Weindling M, eds. Neonatology. Cham: Springer; 2017, p. 1-22.

36. Ornoy A., Ergaz Z. Parvovirus B19 infection during pregnancy and risks to the fetus. Birth Defects Res. 2017;109(5):311-23. doi: 10.1002/ bdra.23588.

37. Crane J., MundleW., Boucoiran I. Parvovirus B19 infection in pregnancy. J Obstet Gynaecol Can. 2014;36(12):1107-16. doi: 10.1016/S17012163(15)30390-X.

38. Waring G.J. Parvovirus B19 infection: Timely diagnosis in pregnancy essential. Case Rep Womens Health. 2018;18:e00057. doi: 10.1016/j. crwh.2018.e00057.

39. Bascietto F., Liberati M., Murgano D. et al. Outcome of fetuses with congenital parvovirus B19 infection: systematic review and metaanalysis. Ultrasound Obstet Gynecol. 2018;52(5):569-76. doi: 10.1002/ uog. 19092.

40. Manaresi E., Gallinella G. Advances in the Development of Antiviral Strategies against Parvovirus B19. Viruses. 2019;11(7). pii: E659. doi: 10.3390/v11070659.

41. Bouthry E., Picone 0., Hamdi G. et al. Rubella and pregnancy: diagnosis, management and outcomes. Prenatal Diagnosis. 2014;34(13):1246-53. doi: 10.1002/pd.4467.

42. Pandolfi E., Gesualdo F., Rizzo C. et al. Global seroprevalence of rubella among pregnant and childbearing age women: a meta-analysis. Eur J Public Health. 2017;27(3):530-37. doi: 10.1093/eurpub/ckw259

43. Voordouw B., Rockx B., Jaenisch T. et al. Performance of Zika Assays in the Context of Toxoplasma gondii, Parvovirus B19, Rubella Virus, and Cytomegalovirus (TORCH) Diagnostic Assays. Clin Microbiol Rev. 2019;33(1). pii: e00130-18. doi: 10.1128/CMR.00130-18.

44. Young M.K., Cripps A.W., Nimmo G.R., van Driel M.L. Post-exposure passive immunisation for preventing rubella and congenital rubella syndrome. Cochrane Database Syst Rev. 2015;(9):CD010586. doi: 10.1002/14651858.CD010586.pub2.

45. Pereira L. Congenital Viral Infection: Traversing the Uterine-Placental Interface. Annu. Rev. Virol. 2018.5:273-99. doi:10.1146/annurevvirology-092917-043236.

46. Khan A.M., Morris S.K., Bhutta Z.A. Neonatal and Perinatal Infections. Pediatr Clin North Am. 2017;64(4):785-98. doi: 10.1016/j. pcl.2017.03.008.

47. Amjadi 0., Rafiei A., Haghshenas M. et al. A systematic review and meta-analysis of seroprevalence of varicella zoster virus: A nationwide population-based study. Journal of Clinical Virology. 2017;87:49-59. doi: 10.1016/j.jcv.2016.12.001

48. Parente S., Moriello N.S., Maraolo A.E., Tosone G. Management of chickenpox in pregnant women: an Italian perspective. Eur J Clin Microbiol Infect Dis. 2018;37(9):1603-09. doi:10.1007/s10096-0183286-7. 
49. Shrim A., Koren G., Yudin M., Farine D. No. 274-Management of Varicella Infection (Chickenpox) in Pregnancy. Journal of Obstetrics and Gynaecology Canada. 2018;40(8):e652-e657. doi: 10.1016/j. jogc.2018.05.034

50. Swamy G.K., Dotters-Katz S.K. Safety and varicella outcomes after varicella zoster immune globulin administration in pregnancy. Am J Obstet Gynecol. 2019;221(6):655-6. doi: 10.1016/j.ajog.2019.07.003

51. Angelova M., Kovachev E., Tsankova V. et al. Role and Importance of Chlamydia Trachomatis. Open Access Maced J Med Sci. 2016;4(3):410-12.

52. Olson-Chen C., Balaram K., Hackney D.N. Chlamydia trachomatis and Adverse Pregnancy Outcomes: Meta-analysis of Patients With and Without Infection. Matern Child Health J. 2018;22(6):812-21. doi: 10.1007/s10995-018-2451-z.

53. Sethi S., Roy A., Garg S. et al. Detection of Chlamydia trachomatis infections by polymerase chain reaction in asymptomatic pregnant women with special reference to the utility of the pooling of urine specimens. Indian J Med Res. 2017;146(Suppl.):S59-S63. doi: 10.4103/ ijmr.IJMR_981_15.

54. Cluver C., Novikova N., Eriksson D.0. et al. Interventions for treating genital Chlamydia trachomatis infection in pregnancy. Cochrane Database Syst Rev. 2017;9:CD010485. doi: 10.1002/14651858. CD010485.pub2.

55. Heumann C.L., Quilter L.A., Eastment M.C. et al. Adverse Birth Outcomes and Maternal Neisseria gonorrhoeae Infection: A Population-Based Cohort Study in Washington State. Sex Transm Dis. 2017;44(5):266-71. doi: 10.1097/0LQ.0000000000000592.

56. Shannon C.L., Klausner J.D. Keep Screening! Maternal Gonococcal Infection and Adverse Birth Outcomes. Sex Transm Dis. 2017;44(5):2723. doi: 10.1097/0LQ.0000000000000630.

57. Warr A.J., Pintye J., Kinuthia J. et al. Sexually transmitted infections during pregnancy and subsequent risk of stillbirth and infant mortality in Kenya: a prospective study. Sex Transm Infect. 2019;95:60-66 doi: 10.1136/sextrans-2018-053597.

58. Comunián-Carrasco G., Peña-Martí G.E., Martí-Carvajal A.J. Antibiotics for treating gonorrhoea in pregnancy. Cochrane Database Syst Rev. 2018;2:CD011167. doi: 10.1002/14651858.CD011167.pub2.

59. Vainder M., Kives S., Yudin M.H. Screening for Gonorrhea and Chlamydia in Pregnancy: Room for Improvement. J Obstet Gynaecol Can. 2019;41(9):1289-94. doi: 10.1016/j.jogc.2019.02.006.

60. Raabe V.N., Shane A.L. Group B Streptococcus (Streptococcus agalactiae). Microbiol Spectr. 2019;7(2). doi: 10.1128/microbiolspec.GPP3-0007-2018.

61. Dai W., Zhang Y., Xu Y. et al. The effect of group B streptococcus on maternal and infants' prognosis in Guizhou, China. Biosci Rep. 2019;39(12). pii: BSR20191575. doi: 10.1042/BSR20191575.

62. Vornhagen J., Adams Waldorf K.M., Rajagopal L. Perinatal Group B Streptococcal Infections: Virulence Factors, Immunity, and Prevention Strategies. Trends Microbiol. 2017;25(11):919-31. doi: 10.1016/j. tim.2017.05.013. Epub 2017 Jun 17.

63. Cho C.Y., Tang Y.H., Chen Y.H. et al. Group B Streptococcal infection in neonates and colonization in pregnant women: An epidemiological retrospective analysis. J Microbiol Immunol Infect. 2019;52(2):265-72. doi: 10.1016/j.jmii.2017.08.004.

64. Prevention of Group B Streptococcal Early-Onset Disease in Newborns: ACOG Committee Opinion Summary, Number 782. Obstet Gynecol. 2019;134(1):206-10. doi: 10.1097/A0G.0000000000003335.

65. Cagno C.K., Pettit J.M., Weiss B.D. Prevention of perinatal group B streptococcal disease: updated CDC guideline. Am Fam Physician. 2012;86(1):59-65.
66. Kladova 0.V., Andzhel A.E., Kompaniets Yu.V. et al. K voprosu differencialnoj diagnostiki listerioza [To the issue of differential diagnosis of listeriosis]. Children's infections. 2019;18(3):61-6. doi: 10.22627/2072-8107-2019-18-3-61-66. (Ru)

67. Wolfe B., Wiepz G.J., Schotzko M. et al. Acute Fetal Demise with First Trimester Maternal Infection Resulting from Listeria monocytogenes in a Nonhuman Primate Model. mBio. 2017;8(1). pii: e01938-16. doi: 10.1128/mBio.01938-16.

68. Craig A.M., Dotters-Katz S., Kuller J.A., Thompson J.L. Listeriosis in Pregnancy: A Review. Obstet Gynecol Surv. 2019;74(6):362-8. doi: 10.1097/0GX.0000000000000683.

69. Moran L.J., Verwiel Y., Bahri Khomami M. et al. Nutrition and listeriosis during pregnancy: a systematic review. J Nutr Sci. 2018;7:e25. doi: 10.1017/jns.2018.16.

70. Pucci L., Massacesi M., Liuzzi G. Clinical management of women with listeriosis risk during pregnancy: a review of national guidelines. Expert Rev Anti Infect Ther. 2018;16(1):13-21. doi: 10.1080/14787210.2018.1417837/

71. Allerberger F., Huhulescu S. Pregnancy related listeriosis: treatment and control. Expert Rev Anti Infect Ther. 2015:13:395-403. doi: 10.1586/14787210.2015.1003809

72. Rogerson S.J. Management of malaria in pregnancy. Indian J Med Res. 2017;146(3):328-33. doi: 10.4103/ijmr.IJMR_1304_17

73. Barateiro A., Pereira M.L.M., Epiphanio S., Marinho C.R.F. Contribution of Murine Models to the Study of Malaria During Pregnancy. Front Microbiol. 2019;10:1369. doi: 10.3389/fmicb.2019.01369.

74. Barboza R., Hasenkamp L., Barateiro A. et al. Fetal-Derived MyD88 Signaling Contributes to Poor Pregnancy Outcomes During Gestational Malaria. Front Microbiol. 2019;10:68. doi: 10.3389/fmicb.2019.00068.

75. Harrington W.E., Kakuru A., Jagannathan P. Malaria in pregnancy shapes the development of foetal and infant immunity. Parasite Immunol. 2019;41(3):e12573. doi: 10.1111/pim.12573.

76. Dunay I.R., Gajurel K., Dhakal R. et al. Treatment of Toxoplasmosis: Historical Perspective, Animal Models, and Current Clinical Practice. Clin Microbiol Rev. 2018;31(4). pii: e00057-17. doi: 10.1128/CMR.00057-17.

77. Di Mario S., BaseviV., GagliottiC. et al. Prenatal education for congenital toxoplasmosis. Cochrane Database Syst Rev. 2013;(2):CD006171. doi: 10.1002/14651858.CD006171.pub3.

78. Montoya J.G. Systematic screening and treatment of toxoplasmosis during pregnancy: Is the glass half full or half empty? Am J Obstet Gynecol. 2018;219:315-19.

79. SadiquiS., Shah S.R.H., Almugadam B.S. et al. Distribution of Toxoplasma gondii $\operatorname{lgM}$ and $\lg \mathrm{G}$ antibody seropositivity among age groups and gestational periods in pregnant women. Version 3. F1000Res. 2018;7:1823. doi: 10.12688/f1000research.15344.3.

80. Peyron F., L'ollivier C., Mandelbrot L. et al. Maternal and Congenital Toxoplasmosis: Diagnosis and Treatment Recommendations of a French Multidisciplinary Working Group. Pathogens. 2019;8(1). pii: E24. doi: 10.3390/pathogens8010024.

\section{ORCID and contributionship:}

Liudmyla A. Vygivska: 0000-0002-9389-4845

Lesia A. Rudenko: 0000-0003-0556-8263 ${ }^{B, E}$

Violeta B. Kalnytska: 0000-0003-4221-2610

Olena Yu. Litvinenko: 0000-0002-6429-8171 E,F

\section{Conflict of interest:}

The Authors declare no conflict of interest 


\section{CORRESPONDING AUTHOR}

Liudmyla A. Vygivska

Kharkiv National Medical University

Nauky Av. 4, 61000, Kharkiv, Ukraine

tel: +380509675487

e-mail: liudmilavygovskaya@gmail.com

Received: 24.04 .2020

Accepted: 26.08 .2020

A - Work concept and design, B - Data collection and analysis, C - Responsibility for statistical analysis,

D-Writing the article, $\mathbf{E}$ - Critical review, $\mathbf{F}$ - Final approval of the article 